\title{
Fairness of Power System Load-Shedding Plans
}

\author{
Evelyn Heylen*, Marten Ovaere ${ }^{\dagger}$, Dirk Van Hertem* and Geert Deconinck* \\ ${ }^{*}$ Department of Electrical Engineering \\ KU Leuven - EnergyVille, Leuven, Belgium \\ Email: evelyn.heylen@esat.kuleuven.be \\ ${ }^{\dagger}$ Department of Economics \\ KU Leuven, Leuven, Belgium
}

\begin{abstract}
Transmission system operators apply selective loadshedding plans to prevent system wide interruptions and blackouts due to generation and transmission adequacy issues. If the load-shedding plan is activated, the electricity supply is intentionally switched off in indicated areas for a fixed period of time. The burden of load-shedding plans thus falls on a subset of consumers, while the benefits accrue to all consumers. This results in public opposition as illustrated with the publication of the loadshedding plan in Belgium in the winter of 2014 - 2015. To improve the social acceptability of load-shedding plans, we analyzed the unfairness of load-shedding plans based on Gini-based inequality indices and studied a top-down socialized compensation scheme and bottom-up priority service contracts to indirectly reduce the unfairness. The analysis is executed for a simplified version of the Belgian load-shedding plan for the winter of 2014 - 2015.
\end{abstract}

Index Terms-Power system reliability, load-shedding plan, fairness, inequality, inequity

\section{INTRODUCTION}

Reliable electricity supply is crucial in modern societies. The estimated cost of a one day blackout equals $0.5 \%$ of the gross domestic product of a country. This should be complemented with social consequences, such as diseases, injuries and deaths [1]. Studies have shown that a one hour blackout of the Belgian power system during working hours would result in an economic loss of $€ 120$ million/hour [2].

Underfrequency load-shedding (UFLS) plans are put in place to avoid blackouts or uncontrolled failures in power systems. Automatic underfrequency load-shedding schemes handle contingencies that happen suddenly and cannot be expected in advance. The load shedding happens automatically using frequency relais in the substations 11 Besides automatic underfrequency load shedding, TSOs with adequacy issues due to insufficient generation or transmission capacity have the capability and authority to carry out controlled load shedding to prevent uncontrolled failures and blackouts. The TSO creates a load-shedding plan to coordinate this controlled load shedding and activates this plan preventively during peak hours when generation deficits are expected. Load-shedding plans typically rely on rolling blackouts, during which the electricity supply is intentionally switched off in indicated areas for a fixed period

The research of Evelyn Heylen is funded by a PhD Fellowship of the Research Foundation Flanders.

${ }^{1}$ Load shedding corresponds to intentional, controlled power cuts to avoid wider and uncontrolled problems. An example of the application of underfrequency load shedding in Europe was the incident on November 4, 2006 [3]. A comparison of different emergency UFLS schemes can be found in [4]. of time. The load-shedding plan is a measure of last resort to overcome adequacy issues if voluntary load reductions and interruptible load contracts prove to be insufficient. The plan is stratified, i.e., multiple slices can be activated to solve the issue, load shedding is spread geographically to avoid instabilities and voltage issues and the priority of the different consumer types, as written in the law, is considered [3].

Although load-shedding plans are a technical measure to prevent system wide blackouts, the social acceptability of loadshedding plans is crucial to make them applicable in practice. Consumers' characteristics are barely considered in the design of load-shedding plans so far. Moreover, the burden of the load-shedding falls on a subset of consumers, while at the same time the benefits accrue to all consumers. Consumers can perceive these measures as unfair, which can result in public opposition against this injustice [5]. To improve the social acceptability, it is crucial to involve consumers in the design process and monitor human-centred aspects driving social acceptability, such as the perceived fairness [6]. Nevertheless, literature mainly focuses on technical aspects of loadshedding plans, especially automatic underfrequency loadshedding plans applied in emergency conditions [4].

To improve the human-centred aspects of selective loadshedding plans, we assessed the perceived fairness of selective load-shedding plans and studied measures to reduce the unfairness. We applied Gini-based fairness indices to assess consumers' perceived fairness of load curtailment resulting from the activation of a selective load-shedding plan. The generic formulation of the Gini-based fairness indices and their strengths and weaknesses are discussed in more detail in a paper of the same authors that is currently under review [7]. We applied the Gini-based fairness indices in a case study for a simplified version of the Belgian load-shedding plan of the winter of 2014 - 2015. System adequacy was low at that time due to the retirement and mothballing of conventional power plants, supplemented by the unforeseen closure of three large nuclear units as a result of indication of micro-cracks in two of the reactor vessels and an outage due to sabotage. Public opposition to the proposed load-shedding plan was large due to the perceived unfairness. We studied two measures to reduce unfairness of selective load-shedding plans and applied them in the case study: a top-down approach using socialized compensation schemes and a bottom-up approach using priority service contracts. 
Section [II discusses fairness in a power system reliability context. Section IIII describes the indices to assess the unfairness of load-shedding plans ${ }^{2}$ Section IV focuses on the assessment of unfairness of a simplified version of the Belgian load-shedding plan of 2014-2015. Section V describes the two measures to reduce the unfairness. Section VI concludes the paper.

\section{FAIRNESS IN A POWER SYSTEM RELIABILITY CONTEXT}

Equality and equity are appropriate distributive norms to define fairness in a power system reliability context ${ }^{3}$ Equity is defined as giving everyone what they deserve based on their inputs, whereas equality is defined as treating everyone the same, regardless of their inputs [9].

This section translates the definition of equality to the power system reliability context and specifies an inequality ratio. The inequality ratio expresses whether a certain entity, i.e., node, consumer group or individual consumer, is treated equally and depends on the consumer's share in total demand and its share in total unreliability expressed in terms of a reliability indicator. Equality is considered from a physical and economic perspective.

\section{A. Inequality of energy not supplied}

Inequality can be defined in terms of energy not supplied (ENS). The inequality ratio in this case equals:

$$
\rho_{j}^{E N S}=\frac{E N S_{j}}{\sum_{j^{\prime} \in \mathcal{J}} E N S_{j^{\prime}}} \cdot \frac{\sum_{j^{\prime} \in \mathcal{J}} D_{j^{\prime}}^{E}}{D_{j}^{E}}
$$

This implies that a set of consumers is considered to be treated equally if their share in total energy not supplied equals their share in total demand, irrespective of their characteristics. Depending on whether the index is used in an ex-ante or expost evaluation, resp. expected energy not supplied (EENS) for a set of events or Energy Not Served (ENS) for a single event or a sequence of events is used.

\section{B. Socio-economic inequality}

Inequality can also be defined in terms of total cost borne by consumers $C_{j}^{c o n s}$, i.e., the interruption cost due to load curtailment, received compensations and payments made in the context of a compensation scheme:

$$
\rho_{j}^{C C}=\frac{C_{j}^{c o n s}}{\sum_{j^{\prime} \in \mathcal{J}} C_{j^{\prime}}^{c o n s}} \cdot \frac{\sum_{j^{\prime} \in \mathcal{J}} D_{j}^{E}}{D_{j}^{E}}
$$

This definition of equality implies that a consumer is treated fairly, if its share in the total cost borne by all consumers equals its share in total demand, i.e., consumers with a higher demand have more costs. This definition can be usefully applied to verify the effectiveness of a socialized compensation scheme.

\footnotetext{
${ }^{2} \mathrm{~A}$ generic discussion of unfairness in a power system reliability contex and the unfairness indices can be found in [7], which is currently under review. The authors applied similar indices in [8].

${ }^{3}$ Donelson Forsyth distinguished five distributive norms: equality, equity, power, need and responsibility. Power, need and responsibility are challenging to assess in a power system reliability context and are out of the scope of this work $[9]$.
}

\section{AN INEQUALITy INDEX FOR POWER SYSTEM RELIABILITY}

Inequality indices enable the quantification of inequality of power system reliability in a single value. Many different inequality indices have been proposed in the economic literature. These indices are used to compare income distributions between countries or to verify the impact of certain decisions, such as the introduction of a tax on the distribution of income within a certain country. Inequality indices have also been applied to insurance [10], education [11] and biodiversity [12]. Only variance-based indices are applied in a power system reliability context. Nevertheless, Gini-based indices have advantages compared to variance-based measures, because the distribution of reliability among end-consumers is typically not symmetric and might be highly skewed [7], [13]. This section elaborates on the calculation of the applied inequality index.

\section{A. Lorenz Curves}

The distribution of reliability between consumers can be represented in a Lorenz curve. A Lorenz curve gives the cumulative share of unreliability $E_{k}$ as a function of the cumulative share of demand $D_{k}$, with all consumers ranked according to an increasing inequality ratio $\rho_{j}$. The inequality ratio determines the slope of the different pieces of the piecewise-linear Lorenz curve. This is shown in Fig. 1

If the distribution of reliability is completely fair (i.e., when $\rho_{j}^{E N S}=1 \forall j \in \mathcal{J}$ ), the Lorenz curve is a straight line with coefficient of direction equal to 1 , as illustrated by the dotted line in Fig. 1 If the distribution of reliability is not completely fair, the Lorenz curve will be below the equality line, as illustrated by the bold line in Fig. 1. The closer the Lorenz curve is to the equality line, the more equal the distribution of reliability.

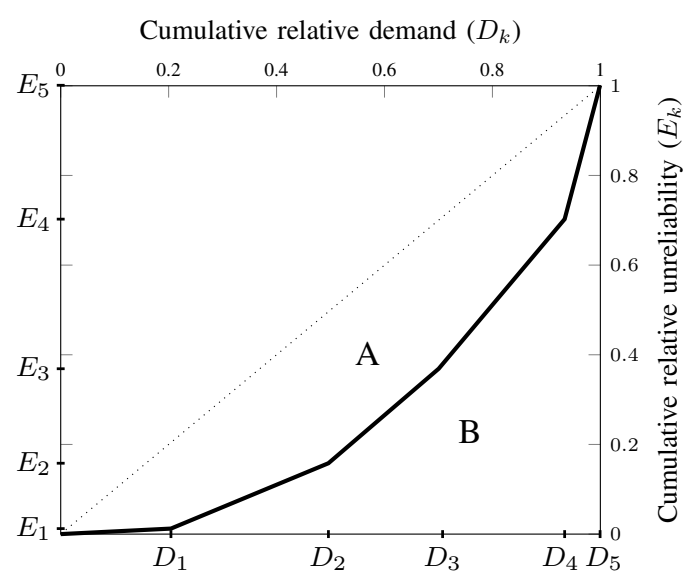

Fig. 1: Lorenz curve in terms of unreliability in a power system context. The line of equality is dotted.

\section{B. Gini-based Inequality Index of Power System Reliability}

The ratio of the surface area between the line of equality and the Lorenz curve (A) over the total surface area under the line 
of equality $(\mathrm{A}+\mathrm{B})$ defines the applied Gini-based inequality index of power system reliability $U$ :

$$
U=\frac{A}{A+B}
$$

The surface areas of the trapezoids under each of the pieces of the piecewise-linear Lorenz curve determine the surface are $B$. This leads to the following formula for $U$ :

$$
U=1-\sum_{k=1}^{J}\left(D_{k}-D_{k-1}\right)\left(E_{k}+E_{k-1}\right)
$$

with $D_{k}$ the cumulative proportion of relative demand $\left(D_{k}=\right.$ $\sum_{j=1}^{k} d_{j} \forall k=1 . . J, D_{0}=0$ and $\left.D_{J}=1\right)$ and $E_{k}$ the cumulative proportion of relative unreliability $\left(E_{k}=\right.$ $\sum_{j=1}^{k} e_{j} \forall k=1 . . J, E_{0}=0$ and $\left.E_{J}=1\right)$. The consumers $j$ are ranked such that $\rho_{j} \leq \rho_{j+1}$.

The proposed index is a direct measure of inequality on a bounded zero-one scale. Unreliability is distributed equally among all consumers if $U$ equals zero. If the inequality index approaches one, the more unreliability is limited to a few consumers.

\section{CAse Study: Fairness of a Simplified Version of THE 2014-2015 BELGIAN LOAD-SHEDDING PLAN}

This section quantifies the inequality for a simplified version of the load-shedding plan introduced in Belgium in the winter of 2014-2015.

\section{A. Data and Assumptions}

The Belgian load-shedding plan for the winter of 20142015 divided Belgium in 5 zones and each zone was further divided into 6 slices ${ }^{4}$ Each slice corresponded to $520 \mathrm{MW}$ of sheddable load, resulting in a total foreseen sheddable load of $3120 \mathrm{MW}$, as summarized in Fig. 2 During load shedding, one of the slices of $520 \mathrm{MW}$ is disconnected for around 3 hours according to a rotation system. Slices within a particular zone are determined based on their geographical location to guarantee geographical spreading and on priorities described in the law.

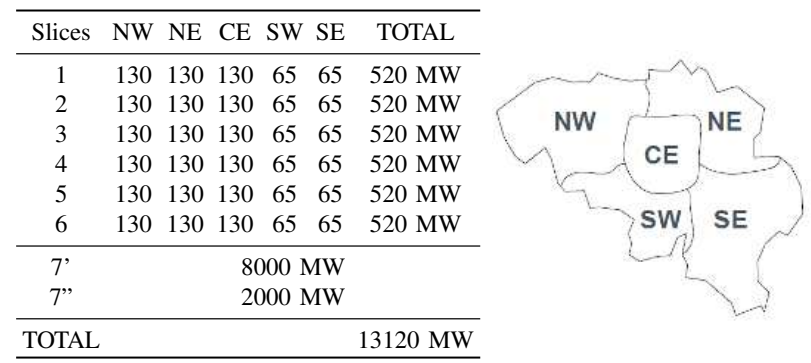

Fig. 2: The division of Belgium into zones and slices according to the load-shedding plan in the winter of 2014-2015 (Data: ELIA).

\footnotetext{
${ }^{4} \mathrm{~A}$ recent update of the load-shedding plan uses 8 slices each corresponding to $500 \mathrm{MW}$ up to $750 \mathrm{MW}$ instead of 6 slices of $520 \mathrm{MW}$ [14].
}

Total system load is assumed to be $13120 \mathrm{MW}$, which means that $10 \mathrm{GW}$ of load is never affected. These consumers are considered to be in slices 7' and 7'. Slice 7' represents densely populated areas with $8 \mathrm{GW}$ of consumers with a low value of lost load (VOLL), whereas slice 7" represents $2 \mathrm{GW}$ of critical high-VOLL consumers 5

\section{B. Results}

Table II gives the share of each slice in total demand and total energy not supplied, resp. $\mathbf{d}$ and $\mathbf{e}$, and the inequality index $U^{\text {ENS }}$ between the slices of the load-shedding plan after 1 up to 6 geographical rotations. That is, $\mathbf{e}_{6}$ is calculated based on the aggregated ENS after 6 rotations, assuming that each time a different slice is affected. Power demand and load curtailment are assumed to last for a fixed time period $\Delta t$ (typically $3 \mathrm{~h}$ ), i.e., $D_{z}^{E}=P_{z}^{D \text {,tot }} \cdot \Delta t$ with $P_{z}^{D \text {,tot }}$ the power demand of slice $z[\mathrm{MW}]$ and $E N S_{z}=P_{z}^{c u r t} \cdot \Delta t$ with $P_{z}^{\text {curt }}$ the load curtailment of slice $z$ [MW]. Only consumers with similar characteristics are considered in the calculation of $U^{\mathrm{ENS}}$, i.e., slice 7 " is omitted. From Table $\mathrm{I}$, it is clear that, under the given assumptions, inequality decreases if load shedding is applied more often. Rotation between the different slices implies that those consumers who have been treated very unfairly with the first action receive a favorable treatment in the next one. However, because a large share of demand remains unaffected (slice 7'), inequality is still high, i.e., $U^{\mathrm{ENS}}$ close to 1 , even after shedding each of the 6 slices once.

TABLE I: $U^{\text {ENS }}$ after 1 up to 6 rotations of the loadshedding plan proposed in Fig. 2, only considering low-VOLL

\begin{tabular}{|c|c|c|c|c|c|c|c|}
\hline \multirow{2}{*}{$\begin{array}{c}\text { Slice } \\
z\end{array}$} & \multirow[b]{2}{*}{ d } & \multicolumn{6}{|c|}{ e for the six rotations } \\
\hline & & $\mathbf{e}_{1}$ & $\mathbf{e}_{2}$ & $\mathbf{e}_{3}$ & $\mathbf{e}_{4}$ & $\mathbf{e}_{5}$ & $\mathbf{e}_{6}$ \\
\hline 1 & 0.047 & 1 & 0.5 & 0.333 & 0.25 & 0.2 & 0.167 \\
\hline 2 & 0.047 & 0 & 0.5 & 0.333 & 0.25 & 0.2 & 0.167 \\
\hline 3 & 0.047 & 0 & 0 & 0.333 & 0.25 & 0.2 & 0.167 \\
\hline 4 & 0.047 & 0 & 0 & 0 & 0.25 & 0.2 & 0.167 \\
\hline 5 & 0.047 & 0 & 0 & 0 & 0 & 0.2 & 0.167 \\
\hline 6 & 0.047 & 0 & 0 & 0 & 0 & 0 & 0.167 \\
\hline 7 & 0.719 & 0 & 0 & 0 & 0 & 0 & 0 \\
\hline & & 0.95 & 0.91 & 0.86 & 0.81 & 0.77 & 0.72 \\
\hline
\end{tabular}
consumers.

It should be noted that the effect on the inequality in this case study can be considered as a marginal effect. Depending on the initial distribution of reliability, some decisions might make the overall distribution of reliability more equal. In a practical setting, the effect of decisions on the existing distribution of unreliability should be assessed. The initial distribution of reliability among consumers in this case study is assumed to be equal.

The authors assessed the inequality $U^{E N S}$ between counties in Norway based on real, detailed reliability data for 20062016 in [7]. The average $U^{E N S}$ over this time period equals

\footnotetext{
${ }^{5}$ These assumptions are a simplification of the real situation to obtain an illustrative case study. In reality, consumers in different slices are more diversified and more subgroups can be considered in the different slices, especially in the unaffected slice 7.
} 
0.34 and the maximum value 0.49 . These values can serve as a comparing reference for the values of $U^{E N S}$ in Table I

\section{Measures to REDUCE UnFAIRnESS OF LOAD-SHEDDING PLANS}

Although it is difficult to obtain equality of reliability between consumers in the practical application of selective load-shedding plans, it is possible to distribute the economic consequences of the activation of load-shedding plans more equally over all consumers in the system. Two approaches are investigated in this paper: a top down socialized compensation scheme and bottom up priority service contracts.

\section{A. Socialized compensation schemes}

By compensating affected consumers, part of the economic burden is shared by all consumers and consequences of an interruption will be distributed more equally. The use of compensation schemes is a top down approach: system operators estimate the value of lost load of different consumers and determine compensations based on these estimations.

Table II shows the impact of compensating affected consumers based on the amount of energy not supplied. The compensation per MWh equals a percentage of the weighted average VOLL of the affected consumers, ranging from no compensation up to a compensation equal to $100 \%$ of the weighted average VOLL. The weighted average is equal to $V^{c o m p}=\sum_{j \in \mathcal{J}} e_{j} \cdot V_{j}$, with $e_{j}$ the share of ENS of consumer $j$ in the total ENS and $V_{j}$ the VOLL of consumer $j$. The economic burden of the compensation is shared between all consumers and is divided according to their demand share, for example through energy-based transmission tariffs. In this illustrative case, the VOLL of the affected consumers is assumed to be equal. The inequality index is calculated based on the inequality ratio in Eq. (2). Inequality can be significantly reduced if a compensation scheme is put in place, even in the case of partial compensation. $100 \%$ compensation results in complete equality under these assumptions.

In practice, VOLL differs between consumers in the affected slices. Moreover, the exact interruption cost per consumer is hard to determine. If interruptions are compensated at average VOLL, some consumers will be over-compensated, whereas others will be under-compensated, resulting in a remaining level of inequality between the consumers.

TABLE II: Evolution of inequality $U^{\mathrm{CC}}$ in terms of net total cost borne by the consumers as a function of the number of rotations and the relative amount of compensation.

\begin{tabular}{c|cccccc}
\hline \multirow{2}{*}{ Compensation } & 1 & 2 & 3 & 4 & 5 & 6 \\
\hline $0 \%$ & 0.95 & 0.91 & 0.86 & 0.81 & 0.77 & 0.72 \\
$30 \%$ & 0.70 & 0.66 & 0.63 & 0.60 & 0.56 & 0.53 \\
$50 \%$ & 0.52 & 0.49 & 0.47 & 0.44 & 0.41 & 0.39 \\
$80 \%$ & 0.22 & 0.21 & 0.20 & 0.19 & 0.17 & 0.16 \\
$100 \%$ & 0 & 0 & 0 & 0 & 0 & 0 \\
\hline
\end{tabular}

\section{B. Priority service contracts}

Priority service contracts enable end-consumers to express their need or desire for power system reliability. With this approach, load can be shed according to the revealed priority instead of randomly. Control shifts from centralized switching of substations at lower voltage levels to decentralized control at the level of the individual household using smart metering, control and communication. Consumers can for instance install a critical and non-critical circuit in their house. The smart metering system can give control to the system operator to disconnect the non-critical system in case of problems, if this is part of the agreed contract. Alternatively, sheddable load can be aggregated by aggregators that receive a signal from the TSO and forward this to the households. Load response can then be activated using direct load control of devices and appliances or the aggregator can send a signal to the consumer with a request to reduce the demand up to a certain level by a certain time as agreed upon in the contract. Load can be reduced manually or automatically using smart plugs. If load is not sufficiently reduced, this results either in a full power interruption of the household or a penalty fee to be paid [15].

An advantage of priority service contracts is that consumers can distinguish between critical and non-critical load. This enables system operators to spread load shedding over more consumers and avoids disconnections of a limited set of consumers in the system. If consumers are served according to the agreed contract, the energy not supplied is not necessarily equally distributed among consumers, but the inequity decreases as consumers are served according to their inputs in terms of the tariff. If for technical reasons the system operator cannot comply with the reliability tariff scheme, inequity exists in the system. However, penalty schemes can be agreed upon in the contract to overcome this inequity.

As an illustration of priority service contracts, we determine the maximal number of days that the set-up of the loadshedding plan in Fig. 2 can be applied for a given priority service contract menu and a certain amount of sheddable load that participates in the priority service contract scheme. The amount of sheddable load is a variable parameter in the analysis. The applied priority service contract menu uses a demand subscription fee. The reliability service is indicated in terms of interruption frequency 6

1) Data: The division in zones and slices as introduced in Fig. 2 is used. Two consumer types, i.e., residential and non-residential consumers, are considered per zone. Tables III IV] V] and VI summarize resp. the applied priority service contract menu with the cost per contracted $\mathrm{kW}$ load $C_{k}$ and the allowed frequency of curtailment $f_{k}$ for each contract $k$ [15], the total demand for a respective load type with value of lost load $V O L L_{i}$ per zone $j P_{i, j}^{D, t o t}$, the share of demand per consumer group $c$ in each zone $D_{j, c}^{\text {share }}$ and the share of demand with $V O L L_{i}$ in the total demand of a consumer type

\footnotetext{
${ }^{6}$ An overview of alternative ways to implement priority service contracts is given in [15].
} 
$V_{i, c}^{\text {share }} 7$

TABLE III: Contract menu [Based on [15]]

\begin{tabular}{l|cccccc}
\hline & \multicolumn{7}{|c}{ Contract $k$} \\
& 1 & 2 & 3 & 4 & 5 & 6 \\
\hline$C_{k}[€ / \mathrm{kw}]$ & 84 & 72 & 48 & 30 & 12 & 0 \\
$f_{k}$ [curt. days/year] & 0.02 & 0.1 & 1 & 5 & 15 & 30 \\
\hline
\end{tabular}

TABLE IV: Demand per zone and value of lost load

\begin{tabular}{|c|c|c|c|c|c|c|}
\hline $\begin{array}{l}\text { Load type } \\
\text { i }\end{array}$ & NW & $P_{i, j}^{D, t o t}$ & $\begin{array}{l}\text { or the } \\
\mathrm{CE}\end{array}$ & $\begin{array}{l}\text { nes } j \\
\text { SW }\end{array}$ & SE & $\begin{array}{l}V O L L_{i} \\
{[€ / \mathrm{kWh}]}\end{array}$ \\
\hline 1 & 410 & 410 & 410 & 205 & 205 & 200 \\
\hline 2 & 410 & 410 & 410 & 205 & 205 & 50 \\
\hline 3 & 1230 & 1230 & 1230 & 615 & 615 & 10 \\
\hline 4 & 410 & 410 & 410 & 205 & 205 & 3 \\
\hline 5 & 410 & 410 & 410 & 205 & 205 & 1 \\
\hline 6 & 410 & 410 & 410 & 205 & 205 & 0.5 \\
\hline
\end{tabular}

TABLE V: Demand share per zone and per consumer type

\begin{tabular}{l|ccccc}
\hline Consumer type & \multicolumn{5}{|c}{$D_{j, c}^{\text {share }}$ for zones $j$} \\
$c$ & $\mathrm{NW}$ & $\mathrm{NE}$ & $\mathrm{CE}$ & $\mathrm{SW}$ & $\mathrm{SE}$ \\
\hline Residential & 0.3 & 0.4 & 0.15 & 0.7 & 0.65 \\
Non-residential & 0.7 & 0.6 & 0.85 & 0.3 & 0.35 \\
\hline
\end{tabular}

TABLE VI: VOLL share per consumer type and per load type

\begin{tabular}{l|cccccc}
\hline Consumer type & \multicolumn{6}{|c}{$V_{i, c}^{\text {share }}$ for $V O L L_{i}$} \\
$c$ & 200 & 50 & 10 & 3 & 1 & 0.5 \\
\hline Residential & 0.1 & 0.2 & 0.2 & 0.15 & 0.1 & 0.25 \\
Non-residential & 0.35 & 0.1 & 0.05 & 0.05 & 0.3 & 0.15 \\
\hline
\end{tabular}

2) Optimization formulation: The selection of contracts by the consumers can be modelled as a mixed integer linear program:

$$
\begin{array}{ll}
\min \sum_{j}\left[\sum_{c}\left(\sum_{i}\left(C_{i, j, c}^{I C}+C_{i, j, c}^{\text {tariff }}\right)\right)\right] & \\
\text { s.t. } C_{i, j, c}^{I C}=\sum_{k} S_{i, j, k, c} \cdot P_{i, j, c}^{D} \cdot f_{k} \cdot V_{i, c} \cdot \Delta t & \forall i, j, c \text { (6) } \\
\quad C_{i, j, c}^{\text {tariff }}=\sum_{k} S_{i, j, k, c} \cdot C_{k} \cdot P_{i, j, c}^{D} & \forall i, j, c(7) \\
P_{i, j, c}^{D}=P_{i, j}^{D, \text { tot }} \cdot D_{j, c}^{\text {share }} \cdot \frac{P^{\text {shed }}}{\sum_{i} \sum_{j} P_{i, j}^{D, t o t}} & \forall i, j, c \text { (8) } \\
V_{i, c}=V O L L_{i} \cdot V_{c, i}^{\text {share }} & \forall i, c \\
S_{i, j, k, c} \in\{0,1\} & \forall i, j, k, c \\
\sum_{k} S_{i, j, k, c}=1 & \forall i, j, c
\end{array}
$$

\footnotetext{
${ }^{7}$ The data in Tables IV V and VI are estimated, as we did not find public data on this level of detail.
}

Consumers choose a set of contracts that minimizes their total cost (Eq. (5)), i.e., the interruption cost due to potential activations of the load-shedding plan $C_{i, j_{c}}^{I C}$ (Eq. (6) and the cost due to the tariff $C_{i, j, c}^{\text {tariff }}$ (Eq. (7) $)^{8}$ The interruption cost depends on the value of lost load for a certain load type $i$ of a certain consumer type $c$ (Eq. (9)). $C_{i, j, c}^{I C}$ and $C_{i, j, c}^{\text {tariff }}$ also depend on the amount of load subject to a certain contract $P_{i, j, c}^{D}$ (Eq. (8)). $P_{i, j, c}^{D}$ is expressed as a function of the percentage of the total load that is sheddable. Only residential consumers and small industry and commerce (C\&I) are considered to be sheddable and participate in the priority service contract scheme. The remaining part of the load is assumed to be too critical to curtail or is incorporated in interruptible load contracts that are activated before the loadshedding plan is applied. $P^{\text {shed }}$ is a parameter representing the amount of load that is sheddable and is varied from $2000 \mathrm{MW}$ up to $\sum_{i} \sum_{j} P_{i, j}^{D, t o t}$. Values for $P_{i, j}^{D, t o t}$ are given in Table IV Consumers can choose different contracts $k$ for loads with different VOLL to differentiate between critical and noncritical load. $S_{i, j, k, c}$ is a multidimensional matrix of binary variables indicating whether a certain contract $k$ is chosen by a certain consumer type $c$ in a particular zone $j$ for load type $i$ with $\operatorname{VOLL} L_{i}\left(S_{i, j, k, c}=1\right.$ if contract $k$ is chosen (Eq. (10))). A particular consumer $c$ in zone $j$ can only choose one contract $k$ for load $i$ with a particular value of lost load $V O L L_{i}$ (Eq. (11).

3) Results: We impose that the distribution of sheddable load per slice among the zones of Belgium should correspond to the distribution in the original load-shedding plan (Fig. 2) to prevent voltage and stability issues. The amount of load contracted in each zone per slice for a certain contract $P_{k, j}^{A, s l i c e}$ determines the maximal number of days $T_{j}^{\text {shed }}$ that the original load-shedding plan can be activated in a certain zone per slice. $P_{k, j}^{A, s l i c e}$ equals:

$$
P_{k, j}^{A, s l i c e}=\frac{\sum_{i} \sum_{c} P_{i, j, c}^{\text {Demand }} \cdot S_{i, j, k, c}}{N^{\text {slices }}} \quad \forall k
$$

$N_{\text {slices }}$ equals the number of slices in the system.

$T_{j}^{s h e d}$ then equals the contracted curtailment frequency for which the cumulative available sheddable load $P_{k, j}^{A, c u m, s l i c e}$ is larger than or equal to the sheddable load per slice in the original load-shedding plan $P_{j}^{\text {ref,shed }}$.

$$
T_{j}^{\text {shed }}=\left\{\max (k): P_{k, j}^{A, \text { cum }, \text { slice }} \geq P_{j}^{\text {ref,shed }}, k \in\{1 \ldots K\}\right\}
$$

$$
\text { with } P_{j}^{\text {ref,shed }}=\left\{\begin{array}{l}
130 M W \quad j \in\{N W, C E, N E\} \\
65 M W \quad j \in\{S W, S E\}
\end{array}\right.
$$

$$
P_{k, j}^{A, \text { cum }, \text { slice }}=\sum_{q=K}^{k} P_{q, j}^{A, \text { slice }}
$$

$K$ is the number of contracts available in the contract menu.

${ }^{8} \mathrm{We}$ assume that consumers can be served according to the agreed contract and that load is curtailed if requested. Therefore, no penalty fees are considered in the optimization. 
Fig. 3 shows the maximal number of days that the loadshedding plan can be applied per slice in each zone given an amount of sheddable load $P^{\text {shed }}$ to obtain an equitable case, i.e., consumers are served according to the chosen contract. The maximal number of days that the load-shedding plan can be activated in the system equals the minimal number of days over all zones, because each zone should have sufficient sheddable load available. In the 2014-2015 load-shedding plan of Belgium, the sheddable load equals $3120 \mathrm{MW}$, which corresponds to 0.02 days per year per slice with the given contract menu, simplifications and assumptions. Based on Fig. 3, the sheddable load should equal $12620 \mathrm{MW}$, which corresponds to $96.2 \%$ of the total system load, to be able to activate the load-shedding plan 30 days per year per slice for the given contract menu, simplifications and assumptions.

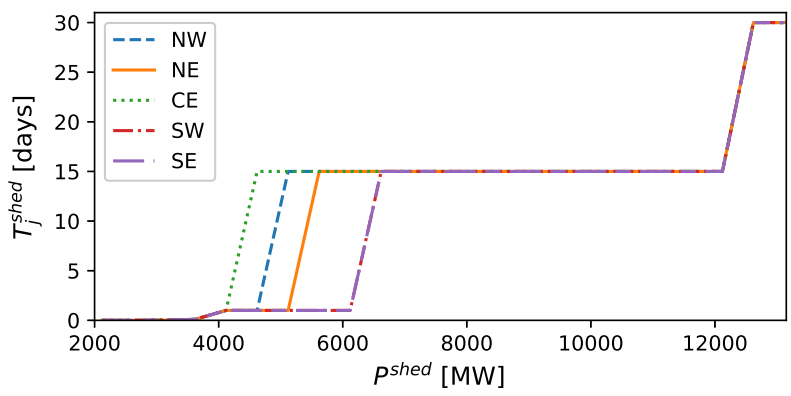

Fig. 3: Maximal number of days that the load-shedding plan can be activated per slice in each zone considering the original design of the load-shedding plan

The analysis enables system operators to assess and revise their load-shedding plans taking into account priority service contracts. Based on the outcomes of the assessment, alternative contract menus can be designed based on the discussions in [15] and [16].

\section{CONCLUSION}

Transmission system operators apply selective loadshedding plans to avoid system wide blackouts in the case of anticipated generation and transmission adequacy issues. Consumers with similar characteristics are treated differently in these load-shedding plans. This implies a perception of unfairness that results in public opposition against a measure that is crucial to ensure power system reliability. This paper assessed the unfairness of load-shedding plans using Ginibased unfairness indices and presented measures to reduce the unfairness indirectly using a top-down or bottom-up approach. The analysis is executed for a simplified version of the Belgian load-shedding plan for the winter of 2014 - 2015.

Top-down socialized compensation schemes using average VOLL reduce inequality. However, inequality still exists due to over- and undercompensations of individual consumers. Bottom-up priority service contracts on the contrary limit inequity, as consumers can indicate their desire for power system reliability. Inequity only arises due to technical constraints that prevent compliance with the prescribed contract menu. A methodology is illustrated that enables system operators to revise their load-shedding plan taking into account the priorities indicated by consumers through priority service contracts. The design of load-shedding plans based on priority service contracts is subject to further research.

\section{REFERENCES}

[1] D. S. Kirschen, "Power system security," Power Engineering Journal, vol. 16 , no. 5, pp. 241-248, 2002.

[2] D. Devogelaer, "Belgian black-outs calculated: A quantitative evaluation of power outages in Belgium [in Dutch]," Federaal Planbureau, Tech. Rep., 2014.

[3] ELIA, "Balance - physical data represented by frequency," ELIA, Tech. Rep., 2012.

[4] B. Delfino, S. Massucco, A. Morini, P. Scalera, and F. Silvestro, "Implementation and comparison of different under frequency loadshedding schemes," in Power Engineering Society Summer Meeting, 2001, vol. 1. IEEE, 2001, pp. 307-312.

[5] S. F. Brosnan and F. B. de Waal, "Evolution of responses to (un) fairness," Science, vol. 346, no. 6207, pp. $1251776-, 2014$.

[6] G. Perlaviciute, G. Schuitema, P. Devine-Wright, and B. Ram, "At the heart of a sustainable energy transition: The public acceptability of energy projects," IEEE Power and Energy Magazine, vol. 16, no. 1, pp. 49-55, 2018.

[7] E. Heylen, M. Ovaere, S. Proost, G. Deconinck, and D. Van Hertem, "Fairness of end-users in power system reliability: Summarizing indices," [Under review], 2018.

[8] E. Heylen, M. Ovaere, G. Deconinck, and D. Van Hertem, "Fair reliability management: Comparing deterministic and probabilistic short-term reliability management," Power and Energy Society General Meeting. Portland, Oregon, USA [Accepted], 2018.

[9] D. R. Forsyth, Group Dynamics. Cengage Learning, 2017, ch. Conflict, pp. 388-389.

[10] D. S. Promislow, "Measurement of equity," Transactions of the Society of Actuaries, vol. 39, pp. 215-256, 1987.

[11] T. Vinod, W. Yan, and F. Xibo, "Measuring education inequality: Gini coefficients of education," World Bank Policy Research Working Paper $2525,2001$.

[12] L. Wittebolle, M. Marzorati, L. Clement, A. Balloi, D. Daffonchio, K. Heylen, P. De Vos, W. Verstraete, and N. Boon, "Initial community evenness favours functionality under selective stress," Nature, vol. 458 , pp. 623-626, 2009.

[13] S. Yitzhaki, "Ginis mean difference: A superior measure of variability for non-normal distributions," Metron, vol. 61, no. 2, pp. 285-316, 2003.

[14] ELIA, "Adequacy study for Belgium: The need for strategic reserve for winter 2017 - 18 and outlook for 2018-19 and 2019-20," [Online] http://www.elia.be/ /media/files/Elia/Products-and-services/ Strategic-Reserve/20161201_Adequacy-Study_EN 2017-2018.pdf 2016.

[15] S. S. Oren, "A historical perspective and business model for load response aggregation based on priority service," in System Sciences (HICSS), 2013 46th Hawaii International Conference on. IEEE, 2013, pp. 2206-2214.

[16] Y. Mou, A. Papavasiliou, and P. Chevalier, "Application of priority service pricing for mobilizing residential demand response in belgium," in European Energy Market (EEM), 2017 14th International Conference on the. IEEE, 2017, pp. 1-5. 